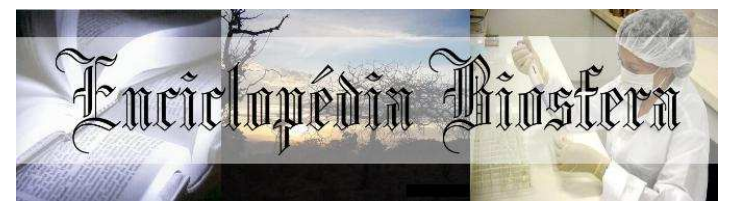

\title{
AVALIAÇÃO DA CITOTOXICIDADE DE TRÊS PLANTAS MEDICINAIS ENCONTRADAS EM QUINTAIS URBANOS NO MUNICÍPIO DE ALTA FLORESTA, MATO GROSSO, BRASIL
}

Patrícia Ana de Souza Fagundes ${ }^{1}$; Jaine de Sousa dos Santos ${ }^{1}$; Jakeline Santos Cochev $^{2}$; Kelli Évelin Müller Zortéa ${ }^{3}$; Ana Aparecida Bandini Rossi ${ }^{4}$.

1. Graduandas do Curso de Ciências Biológicas da Universidade do Estado de Mato Grosso - UNEMAT, Alta Floresta, Mato Grosso, Brasil. E-mail: patricia_ana.fagundes@hotmail.com.

2. Doutoranda em Biodiversidade e Biotecnologia da Amazônia Legal. Universidade do Estado de Mato Grosso - UNEMAT, Alta Floresta, Mato Grosso, Brasil.

3. Mestranda do Programa de Pós-Graduação em Genética e Melhoramento de Plantas - PGMP / Universidade do Estado de Mato Grosso - UNEMAT, Alta Floresta, Mato Grosso, Brasil.

4. Doutora em Genética e Melhoramento de Plantas. Professora da Faculdade de Ciências Biológicas e Agrárias; PPGBioAgro; PGMP; PPGBioNorte - Universidade do Estado de Mato Grosso - UNEMAT, Alta Floresta, Mato Grosso, Brasil.

\section{Recebido em: 02/10/2017 - Aprovado em: 21/11/2017 - Publicado em: 05/12/2017} DOI: 10.18677/EnciBio_2017B70

\begin{abstract}
RESUMO
Este trabalho objetivou avaliar a citotoxicidade de extratos e infusões de boldo, hortelã e capim cidreira, coletadas em quintais do município de Alta Floresta, Mato Grosso, Brasil. A citotoxicidade foi avaliada pelo teste Allium cepa. Avaliou-se quatro concentrações para cada planta: boldo $(20,40,80,160 \mathrm{mg} / \mathrm{mL})$, hortelã $(30,60120$ e $240 \mathrm{mg} / \mathrm{mL}$ ) e capim cidreira $(15,30,60$ e $120 \mathrm{mg} / \mathrm{mL})$. As concentrações foram estipuladas a partir da concentração usual de cada planta. Como controle positivo utilizou-se paracetamol $(5 \mathrm{mg} / \mathrm{mL})$ e como controle negativo água destilada. $\mathrm{O}$ experimento foi montado em DIC, contendo seis tratamentos com cinco repetições por bioensaio. Os bulbos de $A$. cepa foram deixados para germinar nos tratamentos por 48 horas, as raízes germinadas foram coletadas, fixadas em Carnoy 3:1 e armazenadas em etanol $70 \%$. Contou-se 2.000 células por tratamento, anotando-se o número de células em mitose para estabelecer o Índice Mitótico (IM). A concentração usual do extrato de boldo $(80 \mathrm{mg} / \mathrm{mL})$ apresentou IM estatisticamente igual aos controles negativo e positivo, porém mais próximo ao controle negativo. A infusão de hortelã apresentou IM estatisticamente similar ao controle positivo apenas na concentração $240 \mathrm{mg} / \mathrm{mL}$, a concentração usual $(120 \mathrm{mg} / \mathrm{mL})$ não apresentou efeito citotóxico. A concentração usual do capim cidreira $(60 \mathrm{mg} / \mathrm{mL})$ apresentou IM estatisticamente igual ao controle positivo, indicando efeito citotóxico. Recomendase ter cuidado no uso de infusões de capim cidreira, pois a concentração usual apresentou efeito citotóxico. Os valores de IM nas concentrações maiores de extratos e infusões das plantas testadas apresentam decréscimo e similaridade com o controle positivo.
\end{abstract}

PALAVRAS-CHAVE: Boldo, Capim cidreira, Extratos vegetais, hortelã. 


\title{
EVALUATION OF THE CYTOTOXICITY OF THREE MEDICINAL PLANTS FOUND IN URBAN YARDS IN THE MUNICIPALITY OF ALTA FLORESTA, MATO GROSSO, BRAZIL
}

\begin{abstract}
This work aimed to evaluate the cytotoxicity of extracts and infusions of three medicinal plants (boldo, hortelã and campim cidreira) that were collected in yards in the municipality of Alta Floresta, Mato Grosso, Brazil. The citotoxicyty was evaluated through Allium cepa test. We analyzed four concentrations for each plant: boldo (20, $40,80$ and $160 \mathrm{mg} / \mathrm{mL})$, hortelã $(30,60120$ and $240 \mathrm{mg} / \mathrm{mL})$ and capim cidreira (15, 30,60 and $120 \mathrm{mg} / \mathrm{mL}$ ). The concentrations used in the assays were established according to the usual concentration that is consumed by people. Paracetamol (5 $\mathrm{mg} / \mathrm{mL}$ ) was used for positive control, and distilled water for negative control. The experiment was organized in DIC, with six treatments and five replications per assay. The bulbs of $A$. cepa were germinated in the treatments for 48 hours, after the roots germinated were collected, fixed in Carnoy $3: 1$, and stored in $70 \%$ ethanol. To estimate the mitotic index (MI) were evaluated 2000 cells per treatment. The usual concentration of the extract of boldo $(80 \mathrm{mg} / \mathrm{mL})$ presented Ml statistically similar to the negative and positive controls, being more similar to the negative control. The concentration $240 \mathrm{mg} / \mathrm{mL}$ obtained by hortelã infusion presented $\mathrm{Ml}$ similar to the positive control, while the usual concentration $(120 \mathrm{mg} / \mathrm{mL})$ did not present cytotoxic effect. The usual concentration of capim cidreira $(60 \mathrm{mg} / \mathrm{mL})$ presented $\mathrm{MI}$ statistically similar to the positive control, thus indicating cytotoxic effect. We recommended to use with caution capim cidreira infusions, since its usual concentration showed cytotoxic effect. The IM values presented decrease and similarity to the positive control in the higher concentrations of the extracts and infusions analyzed.
\end{abstract}

KEYWORDS: Plant extracts, Boldo, Hortelã, Capim cidreira.

\section{INTRODUÇÃO}

A utilização de plantas no tratamento de doenças é muito comum entre a população desde as primeiras civilizações por conter em sua composição essências e princípios ativos que revelam empiricamente um poder curativo (BADKE et al., 2011). Porém muitas destas plantas não foram estudadas em relação aos potenciais efeitos tóxicos a nível celular (BRAGATINI et al., 2007). Vicentini et al., (2001) afirmam que chás e infusões de algumas plantas podem conter substâncias tóxicas com efeito mutagênico.

Aproximadamente $80 \%$ da população mundial em países em desenvolvimento fazem uso de plantas medicinais para cuidar da saúde, porém apenas 15\% a 17\% destas plantas têm sido estudadas cientificamente para avaliar a eficácia e segurança (SILVA et al., 2015). Entre as espécies utilizadas na medicina popular brasileira, destacam-se o boldo (Plectranthus barbatus Andrews), o capim cidreira (Cymbopogon citratus (DC) Stapf) e a hortelã (Mentha $x$ villosa Huds), pois estão entre as plantas mais citadas em levantamentos etnobotânicos de plantas medicinais do Brasil (NEVES et al., 2012; PERNA; LAMANO-FERREIRA, 2015).

O Plectranthus barbatus Andrews (Lamiaceae) popularmente conhecido como boldo-peludo, falso-boldo e boldo brasileiro (LORENZI; MATOS 2008), é indicado para distúrbios intestinais, patologias hepáticas, cólica abdominal, doenças cardíacas, distúrbios do sistema nervoso e doenças respiratórias como asma, 
bronquite e pneumonia (ALASBAHI; MELZIG, 2010; RODRIGUES et al., 2011).

O gênero Mentha (Lamiaceae) envolve cerca de 30 espécies que podem ser encontradas na América do Sul, sendo que algumas produzem óleos voláteis com potencial de uso nas indústrias farmacêuticas e de alimentos (DORMAN et al., 2003; SERRA et al., 2013) e por isso apresentam grande importância econômica. A hortelã (Mentha $x$ villosa Huds) estimula o aparelho digestório, combate dores de barriga e prisão de ventre e tem propriedades anestésicas devido à presença do mentol, podendo ser usada como emplastos e as folhas amassadas podem ser colocadas sobre picadas de inseto, em hematomas simples, promovendo alívio no local (MARTINS et al., 2002).

Cymbopogon citratus (Poaceae) é conhecido popularmente no Brasil como capim-limão, capim-cidró, capim-cheiroso, capim-cidreira, capim-cidrão, citronela-dejava entre outros (GUIMARÃES et al., 2008). É uma planta que tem origem na Índia e Ásia Oriental, mas que se encontra bastante adaptada nas condições do Brasil, essa planta tem ciclo perene, é caracterizada pela presença de folhas compridas, estreitas e afiadas, atingindo aproximadamente $80 \mathrm{~cm}$ de altura (LORENZI; MATOS 2008). Seu uso é largamente difundido desde a região norte à região sul do país na forma de chá, que pode ser preparado por decocção de folhas secas ou por infusão de folhas frescas (SOUZA et al., 2005). O citral é o composto químico presente em maior quantidade no capim cidreira, ao qual se atribui a atividade calmante $\mathrm{e}$ espasmolítica, é empregado para o alívio de cólicas intestinais e ao tratamento de estados de intranquilidade, farmacologicamente comprovado (LORENZI, 2008).

O índice mitótico indica a proliferação adequada das células e conforme Becavello et al., (2012) é utilizado como parâmetro para análise da citotoxicidade de extratos de plantas e, pode ser medido através do teste de Allium cepa (TEDESCO et al., 2012). Este teste avalia distúrbios no ciclo celular e no índice mitótico de células meristemáticas de cebola e destaca-se para ser aplicado em estudos do efeito de extratos vegetais por ser uma alternativa barata, eficiente, sensível e que apresenta boa correlação com outros sistemas teste (BECAVELLO et al., 2012; FRESCURA et al., 2012; LOUVATEL et al., 2014;).

Diante do exposto, este trabalho objetivou avaliar a citotoxicidade de extratos e infusões das plantas medicinais: boldo, hortelã e capim cidreira, coletadas em quintais do município de Alta Floresta, Mato Grosso, Brasil.

\section{MATERIAL E MÉTODOS}

\section{Área de estudo e material vegetal}

O estudo foi realizado no município de Alta Floresta, MT e teve o auxilio de professores e alunos de duas escolas estaduais da cidade. As folhas de boldo foram coletadas por alunos da Escola Estadual Jayme Verissimo de Campos Junior e as folhas de hortelã e capim cidreira foram coletadas por professores da Escola Estadual Vitória Furlani da Riva, todo o material vegetal foi obtido em quintais dentro do município.

O material vegetal de todas as espécies para a confecção dos extratos e infusões constituiu em folhas frescas. O material coletado foi levado para o laboratório de Genética Vegetal e Biologia Molecular da Universidade do Estado de Mato Grosso, campus Universitário de Alta Floresta. 


\section{Preparação dos extratos e infusões}

A preparação dos extratos e infusões partiu da concentração usual utilizada por populares. A concentração usual foi estimada com base em pesquisa com usuários das plantas. A partir da concentração, usual foram fixadas concentrações inferiores e superiores para cada planta, totalizando sempre quatro concentrações.

Para preparo do extrato de boldo considerou-se a concentração usual de três folhas para $100 \mathrm{~mL}$ de água, que correspondeu a $8 \mathrm{~g}$ de material ou $80 \mathrm{mg} / \mathrm{mL}$. Pesou-se a quantidade necessária de folhas para obtenção de $500 \mathrm{~mL}$ de extrato nas concentrações de 20,40,80, $160 \mathrm{mg} / \mathrm{mL}$. As folhas foram trituradas em liquidificador juntamente com a água destilada e em seguida o extrato foi coado.

A concentração usual utilizada como base para o preparo das infusões de hortelã consistiu em seis folhas para cada $100 \mathrm{~mL}$ de água, o equivalente a $12 \mathrm{~g}$ de folhas ou $120 \mathrm{mg} / \mathrm{mL}$. Pesou-se a quantidade de folhas necessárias para obtenção de $500 \mathrm{~mL}$ de infusão nas concentrações de 30, 60120 e $240 \mathrm{mg} / \mathrm{mL}$. Para preparo da infusão, foram adicionadas as folhas após a água ferver, a infusão ficou em repouso por 10 minutos e em seguida foi coada.

Para a infusão do capim cidreira a concentração usual consistiu em três folhas em $100 \mathrm{~mL}$ de água equivalendo a $6 \mathrm{~g}$ ou $60 \mathrm{mg} / \mathrm{mL}$. Foram pesados na balança de precisão às quantidades de folhas necessárias para preparo de $500 \mathrm{~mL}$ de infusão nas concentrações $15,30,60$ e $120 \mathrm{mg} / \mathrm{mL}$. O preparo das infusões com capim cidreira seguiu o mesmo procedimento das infusões de hortelã. Como controle positivo utilizou-se paracetamol $(5 \mathrm{mg} / \mathrm{mL})$. E como controle negativo utilizou-se água destilada, totalizando seis tratamentos para cada espécie medicinal avaliada.

\section{Montagem do experimento}

Os experimentos foram montados na Escola Estadual Jayme Veríssimo de Campos Júnior, com o auxílio dos alunos das turmas $2^{\circ}$ e $3^{\circ}$ ano do ensino médio. $\mathrm{O}$ delineamento experimental foi inteiramente casualizado, contendo seis tratamentos por bioensaio e cinco repetições por tratamento. Dessa forma, foram utilizados 30 bulbos por bioensaio. Os bulbos foram primeiramente colocados para germinar em água destilada por 24 horas em temperatura ambiente. Após a germinação, os bulbos foram transferidos para os diferentes tratamentos por 48 horas.

Posteriormente as raízes germinadas foram coletadas e fixadas em Carnoy 3:1 (etanol: ácido-acético) por 24 horas em temperatura ambiente e em seguida armazenadas em etanol $70 \%$ a $-4{ }^{\circ} \mathrm{C}$.

\section{Montagem das lâminas e contagem das células}

As lâminas foram preparadas através da técnica de esmagamento proposta por Guerra e Souza (2002). As raízes foram submetidas a uma lavagem em água destilada por cinco minutos, hidrolisadas em HCL 5N (Ácido clorídrico) por 15 minutos e novamente lavadas em água destilada por cinco minutos. Após a lavagem foram colocadas sobre a lâmina e com o bisturi a coifa foi extraída para a obtenção da região meristemática apical, o restante do material foi descartado, deixando sobre a lâmina somente o material em plena atividade celular.

As lâminas foram observadas em microscópio óptico binocular com magnitude de 40X. A contagem das células foi realizada conforme Pires (2001). Foram analisadas oito raízes para cada tratamento, contando-se 250 células por lâmina, totalizando 2.000 células por tratamento. Nas células analisadas foram 
observados números de células em cada fase da mitose: interfase, prófase, metáfase, anáfase e telófase.

\section{Análise dos dados}

A significância do efeito dos tratamentos foi determinada por meio do teste $F$. Para comparação entre os tratamentos foi utilizado o Teste de Tukey $(p<0,05)$. Todas as análises foram realizadas com o programa estatístico SISVAR 5.0 (FERREIRA, 2003).

\section{RESULTADOS E DISCUSSÕES}

Por meio destes bioensaios verificou-se a influência dos extratos de boldo e das infusões de hortelã e de capim cidreira no índice mitótico de $A$. cepa. A tabela 1 apresenta os resultados da análise de variância onde os tratamentos apresentaram alterações significativas para o índice mitótico (IM).

TABELA 1. Quadrado médio da variável Índice Mitótico (IM) de raízes de Allium cepa submetidas a diferentes concentrações de extratos aquosos de boldo e infusões de hortelã e capim cidreira.

\begin{tabular}{cccc}
\hline Fonte de variação & Capim Cidreira & Hortelã & Boldo \\
\hline Tratamento & $353.46^{\star *}$ & $328.46^{\star *}$ & $141.21^{*}$ \\
Média & 56.6 & 52.32 & 54.02 \\
\hline CV $(\%)$ & 9.93 & 11.56 & 13.02 \\
\hline
\end{tabular}

Efeito significativo $1 \%\left({ }^{* *}\right)$ e $5 \%\left({ }^{*}\right)$

Entre os tratamentos com o extrato de boldo, a concentração de $160 \mathrm{mg} / \mathrm{mL}$ apresentou índice mitótico inferior aos demais tratamentos, porém não foi significativamente diferente dos controles positivo e negativo sendo estatisticamente diferente apenas do tratamento com o extrato de $40 \mathrm{mg} / \mathrm{mL}$. De acordo com Iganci et al., (2006), extratos de boldo podem ou não estimular a divisão celular em raízes de cebola. A pequena influência verificada no índice mitótico pode estar relacionada com a presença de substâncias potencialmente tóxicas, como a forscolina (PEREIRA et al., 2014). A concentração usual que corresponde ao extrato de $80 \mathrm{mg} / \mathrm{mL}$, não apresentou diferença significativa em relação aos controles negativo e positivo, porém apresentou IM mais próximo ao controle negativo, sugerindo ausência de efeito citotóxico (Tabela 2).

TABELA 2. Índice mitótico (IM) em raízes de $A$. cepa submetidas e diferentes concentrações de extratos de boldo.

\begin{tabular}{ccc}
\hline Tratamentos & $\begin{array}{c}\text { No de células em } \\
\text { divisão }\end{array}$ & IM (\%) \\
\hline Paracetamol (controle positivo) & 999 & $49.85 \mathrm{ab}$ \\
Água (controle negativo) & 1118 & $55.90 \mathrm{ab}$ \\
Extrato $20 \mathrm{mg} / \mathrm{mL}$ & 1127 & $56.35 \mathrm{ab}$ \\
Extrato $40 \mathrm{mg} / \mathrm{mL}$ & 1192 & $59.60 \mathrm{a}$ \\
Extrato $80 \mathrm{mg} / \mathrm{mL}$ & 1079 & $53.95 \mathrm{ab}$ \\
Extrato $160 \mathrm{mg} / \mathrm{mL}$ & 968 & $48.40 \mathrm{~b}$ \\
\hline
\end{tabular}

Médias seguidas pelas mesmas letras minúsculas na coluna não diferem entre si pelo teste de Tukey a $5 \%$ de probabilidade.

Para a infusão de hortelã apenas o tratamento com $240 \mathrm{mg} / \mathrm{mL}$ apresentou o IM estatisticamente similar ao controle positivo. Os demais tratamentos não foram ENCICLOPÉDIA BIOSFERA, Centro Científico Conhecer - Goiânia, v.14 n.26; p.810 2017 
significativamente diferentes do tratamento controle, (Tabela 3). Esses resultados sugerem que a concentração usual $(120 \mathrm{mg} / \mathrm{mL})$ não apresenta efeito citotóxico sobre as células meristemáticas de cebola.

Trabalhos experimentais feitos sobre os óleos essenciais têm demonstrado que algumas das substâncias que são encontradas na hortelã, em alta quantidade, podem provocar toxicidade (BRASILEIRO et al., 2008). Mas segundo Kamatou et al., (2013) a toxicidade apresentada pelo mentol é baixa. Essas informações podem explicar a influencia mais significativa do tratamento com maior concentração no IM e a diferença não significativa entre os demais tratamentos e o controle.

TABELA 3. Índice mitótico (IM) em raízes de A. cepa submetidas a diferentes concentrações de infusões de hortelã.

\begin{tabular}{ccc}
\hline Tratamentos & $\begin{array}{c}\text { No de células em } \\
\text { divisão }\end{array}$ & IM (\%) \\
\hline Paracetamol (controle positivo) & 851 & $42.55 \mathrm{c}$ \\
Água (controle negativo) & 1070 & $53.50 \mathrm{ab}$ \\
Infusão $30 \mathrm{mg} / \mathrm{mL}$ & 1081 & $54.04 \mathrm{ab}$ \\
Infusão $60 \mathrm{mg} / \mathrm{mL}$ & 1243 & $62.14 \mathrm{a}$ \\
Infusão $120 \mathrm{mg} / \mathrm{mL}$ & 1046 & $52.30 \mathrm{~b}$ \\
Infusão $240 \mathrm{mg} / \mathrm{mL}$ & 987 & $49.35 \mathrm{bc}$ \\
\hline
\end{tabular}

Médias seguidas pelas mesmas letras minúsculas na coluna não diferem entre si pelo teste de Tukey a $5 \%$ de probabilidade.

Os tratamentos com infusão de capim cidreira, com concentração de $60 \mathrm{mg} / \mathrm{mL}$ e $120 \mathrm{mg} / \mathrm{mL}$ apresentaram o IM estatisticamente igual ao controle positivo (Tabela 4). Este resultado pode estar relacionado a metabólitos secundários produzidos pelo capim cidreira como o geraniol, citral e diterpenos que possuem funções ecológicas conhecidas como inibidores de germinação e frequentemente toxidade elevada dependendo da dose manipulada (SOUZA et al., 2005).

O resultado encontrado para o tratamento de $60 \mathrm{mg} / \mathrm{mL}$ que consiste na concentração usual do capim cidreira destaca a importância do conhecimento adequado sobre as doses de uso das plantas medicinais, uma vez que dependendo das concentrações e dos metabólitos presentes podem ter efeitos tóxicos (SILVA et al. 2015).

As infusões em maiores concentrações apresentaram efeito citotóxico nas células de cebola. Resultados semelhantes foram obtidos por Louvatel et al., (2014) que verificaram que o aumento na concentração de infusões de Stachys byzantina C. Koch. (Lamiaceae) causou decréscimo no índice mitótico de células de cebola.

TABELA 4. Índice mitótico (IM) em raízes de $A$. cepa submetidas e diferentes concentrações de infusões de capim cidreira.

\begin{tabular}{ccc}
\hline Tratamentos & $\begin{array}{c}\text { No de células em } \\
\text { divisão }\end{array}$ & IM (\%) \\
\hline Paracetamol (controle positivo) & 937 & $46.85 \mathrm{c}$ \\
Água (controle negativo) & 1207 & $60.35 \mathrm{ab}$ \\
Infusão $15 \mathrm{mg} / \mathrm{mL}$ & 1268 & $63.40 \mathrm{a}$ \\
Infusão $30 \mathrm{mg} / \mathrm{mL}$ & 1257 & $62.85 \mathrm{a}$ \\
Infusão $60 \mathrm{mg} / \mathrm{mL}$ & 1077 & $53.85 \mathrm{bc}$ \\
Infusão $120 \mathrm{mg} / \mathrm{mL}$ & 1045 & $52.25 \mathrm{bc}$ \\
\hline
\end{tabular}

Médias seguidas pelas mesmas letras minúsculas na coluna não diferem entre si pelo teste de Tukey a $5 \%$ de probabilidade. 


\section{CONCLUSÃO}

O extrato de boldo e a infusão de hortelã na concentração usual não apresentaram efeito citotóxico em células de $A$. cepa. Recomenda-se um maior cuidado no uso de infusões de capim-cidreira, pois na concentração usual esta planta apresentou efeito citotóxico. Os valores de IM nas concentrações maiores de extratos e infusões das plantas testadas apresentam decréscimo e similaridade com o controle positivo.

\section{AGRADECIMENTOS}

A FAPEMAT (Fundação de Amparo a Pesquisa do Estado de Mato Grosso), pela concessão de bolsa de iniciação científica do primeiro e segundo autor e bolsa de doutorado para o terceiro autor.

\section{REFERÊNCIAS}

ALASBAHI, RAWIYA H.; MELZIG, MATTHIAS F. Plectranthus barbatus: a review of phytochemistry, ethnobotanical uses and pharmacology-part 1. Planta medicinal, v. 76, n. 07, p. 653-661, 2010. Disponível em < https://www.thiemeconnect.com/products/ejournals/html/10.1055/s-0029-1240919.

DOI: $10.1055 / \mathrm{s}-0029-1240919$

BADKE, M. R.; BUDÓ, M. L. D.; SILVA, F. M.; RESSEL, L. B. Plantas medicinais: o saber sustentado na prática do cotidiano popular. Escola Anna Nery Revista de Enfermagem, v. 15, n. 1, p. 132-139, 2011. Disponível em <https://www.researchgate.net/profile/Marcio_Badke/publication/262447436_Medicin al_plants_the_knowledge_sustained_by_daily_life_practice/links/53db97620cf2a76fb 666a612.pdf>. DOI: http://dx.doi.org/10.1590/S1414-81452011000100019.

BeCAVELLO, L.; CUNHA, M. R. H.; ANDRADE, M. A.; BATITUCCI, M. C. P. Citotoxicidade e danos ao DNA induzidos pelo extrato de Zornia diphylla, uma planta medicinal. Natureza on line, v. 10, n. 3, p. 140-145, 2012. Disponível em < http://www.naturezaonline.com.br/natureza/conteudo/pdf/08_BelcavelloLetal_140145 .pdf > Acesso em 02 de maio de 2017.

BRASILEIRO, B. G.; PIZZIOLO, V. R.; MATOS, D. S.; GERMANO, A. M., \& JAMAL, C. M. Plantas medicinais utilizadas pela população atendida no "Programa de Saúde da Família", Governador Valadares, MG, Brasil. Revista Brasileira de Ciências Farmacêuticas, v. 44, n. 4, 2008. Disponível em < http://www.scielo.br/pdf/rbcf/v44n4/v44n4a09>. DOI: http://dx.doi.org/10.1590/S151693322008000400009. DOI: http://dx.doi.org/10.1590/S0102-695X2007000300019.

BRAGATINI, M. D.; SILVA, A. C. F.; TEDESCO, S. B. Uso do sistema teste de Allium cepa como bioindicador de genotoxicidade de infusões de plantas medicinais. Revista Brasileira de Farmacognosia, v. 17, n. 3, p. 444-447, 2007. Disponível em: <http://www.scielo.br/pdf/rbfar/v17n3/18.pdf>. DOI: http://dx.doi.org/10.1590/S0102695X2007000300019

DORMAN, H. J. D.; KOSAR, M.; KAHLOS, K.; HOLM, Y. HILTUNEN, R. Antioxidant Properties and Composition of Aqueous Extracts from Mentha species, hybrids, varieties, and cultivars. Journal of Agricultural and Food Chemistry, v. 51, n.16, p. 
4563-4569, 2003. Disponível em < http://pubs.acs.org/doi/pdf/10.1021/jf034108k> DOI: $10.1021 / \mathrm{jf034108k}$

FERREIRA, D.F. SISVAR 5.0 Sistema de Análises Estatísticas. Lavras: UFLA, 2003.

FRESCURA, V.D.; LAUGHINGHOUSE IV, H.D.; TEDESCO, S. B. Antiproliferative effect of the tree and medicinal species Luehea divaricata on the Allium Cepa cell cycle. Caryologia, v.65, n.1, p. 27-33, 2012. Disponível em <http://www.tandfonline.com/doi/pdf/10.1080/00087114.2012.678083?needAccess=t rue. DOI: $10.1080 / 00087114.2012 .678083$

GUERRA, M.; SOUZA, M. J. Como observar cromossomos: um guia de técnicas em citogenética vegetal, animal e humana. Ribeirão Preto: FUNPEC, 2002. 201p.

GUIMARÃES, L. G. L.; CARDOSO, M. G.; ZACARONI, L. M.; LIMA R. K. Influência da luz e da temperatura sobre a oxidação do óleo essencial de capim-limão (Cymbopogon citratus (DC) Stapf). Quimica Nova, v. 31, n. 6, p. 1476-1480, 2008. Disponível em < http://quimicanova.sbq.org.br/detalhe_artigo.asp?id=1343>. Acesso em 02 de maio de 2017.

IGANCI, J. R. V.; BOBROWSKI, V. L.; HEIDEN, G.; STEIN, V. C.; ROCHA, B. H. G. Efeito do extrato aquoso de diferentes espécies de boldo sobre a germinação e índice mitótico de Allium cepa L. Revista Arquivos do Instituto Biológico, v. 73, n. 1, p. 79-82, 2006. 2 Disponível em http://www.biologico.sp.gov.br/docs/arq/V73_1/iganci.PDF>. Acesso em 02 de maio de 2017

KAMATOU, G. P.; VERMAAK, I.; VILJOEN, A. M.; LAWRENCE, B. M. Menthol: a simple monoterpene with remarkable biological properties. Phytochemistry, v.96, 15-25. 2013. Disponível em < http://www.sciencedirect.com/science/article/pii/S0031942213003063>

DOl.org/10.1016/j.phytochem.2013.08.005

LORENZI, H.; MATOS, F.J.A. Plantas medicinais no Brasil (nativas e exóticas). São Paulo, p.147-148,2008.

LOUVATEL, K. ARENHART; A. R. ZAIONS, M. I. M. Avaliação da citotoxicidade e genotoxicidade dos extratos de Stachys byzantina C. Koch. (pulmonária) e Tropaeolum majus L.(capuchinha), utilizando o sistema teste Allium Cepa. Unoesc \&

Ciência-Acbs, v. 5, p. 23-28, 2014. Disponível em < http://editora.unoesc.edu.br/index.php/acbs/article/view/4539/pdf_37>.Acesso em 02 de maio de 2017.

MARTINS, E. R.; CASTRO, D. M.; CASTELLANI, D.; DIAS, J. E. Plantas medicinais . 4. ed. Viçosa: EDITORA UFV, 2002.

NEVES, G.; DE OLIVEIRA, E. P.; SILVA, J. K.; BOSSO, M. K.; BÖHM, F. M. L. Z.; STRÖHER, G. L. Determinação do efeito alelopático, índice mitótico e utilização do boldo, capim-cidreira e hortelã no bairro boa vista em Mandaguari (PR). Revista 
Diálogos \& Saberes, v. 8, n. 1, 2012 Disponível em < http://seer.fafiman.br/index.php/dialogosesaberes/article/view/268/260> .Acesso em 02 de maio de 2017.

PERNA, T. A.; LAMANO-FERREIRA, A. P. N.. Revisão bibliométrica sobre o cultivo de plantas medicinais em quintais urbanos em diferentes regiões do Brasil (20092012). Journal of Health Sciences, v. 16, n. 1, 2014. Disponivel em < http://www.pgsskroton.com.br/seer/index.php/JHealthSci/article/view/567/534>. DOI: http://dx.doi.org/10.17921/2447-8938.2014v16n1p\%25p.

PEREIRA, I. R; MALAFAIA, G. Conhecimentos sobre plantas medicinais entre estudantes do Instituto Federal Goiano, campus Urutaí, GO. Saúde e Pesquisa, v. 7, $\quad$ n. 2014.20 Disponível 20 http://periodicos.unicesumar.edu.br/index.php/saudpesq/article/view/3503/2377>. Acesso em 02 de maio de 2017.

PIRES, N. M. Efeito do extrato aquoso de leucena sobre o desenvolvimento, índice mitótico e atividade da peroxidase em plântulas de milho. Revista Brasileira de Fisiologia Vegetal, v.13, n.1, p.55-65, 2001. Disponível em < http://www.scielo.br/pdf/\%0D/rbfv/v13n1/9273.pdf>. $\quad$ DOI: http://dx.doi.org/10.1590/S0103-31312001000100007

RODRIGUES, T. S.; GUIMARÃES, S. F.; RODRIGUES, R. G.; GABRIEL, J. V. Métodos de secagem e rendimento dos extratos de folhas de Plectranthus barbatus (boldo-da-terra) e $P$. ornatus (boldo-miúdo). Revista Brasileira de Plantas Medicinais. Edição especial, v. 13. 2011. Disponivel em <http://www.scielo.br/pdf/rbpm/v13nspe/a14v13nspe.pdf>. DOI: http://dx.doi.org/10.1590/S1516-05722011000500014.

SERRA, L. Z.; SANTOS, G. A.; BRENZAN, M. A.. Influência do cultivo na produção de biomassa, teor e composição do óleo essencial de Mentha spicata. SaBiosRevista de Saúde e Biologia, v. 8, n. 3, 2013. Disponível em < http://revista.grupointegrado.br/revista/index.php/sabios2/article/view/802/537>.

Acesso em 02 de maio de 2017.

SILVA, A. E. P.; MOURA, J. W. M.; LÚCIO NETO, M. P. Avaliação tóxica, citotóxica, genotóxica e mutagênica da Turnera ulmifolia L. (chanana) em células eucarióticas. Revista Saúde em Foco, v. 2, n. 1, p. 25-48, 2015. Disponível em <http://189.43.21.151/revista/index.php/saudeemfoco/article/view/694/842>. Aceso em 02 de maio de 2017.

SOUZA S. A. M.; STEIN V. C.; CATTELAN L. V.; BOBROWSKI V. L.; ROCHA B. H. G. Utilização de sementes de alface e de rúcula como ensaios biológicos para avaliação do efeito citotóxico e alelopático de extratos aquosos de plantas medicinais. Revista de Biologia e Ciências da Terra, v. 5, n. 1, 2005. Disponivel em <Http://http://www.redalyc.org/articulo.oa?id=50050101>. Acesso em 02 de maio de 2017.

TEDESCO, M.; KUHN, A. W.; AGUIAR, A. R.; SILVA, A. C. F.; TEDESCO, S. B. 
Potencial antiproliferativo de extratos aquosos de Mentha pulegium L. pelo teste Allium cepa L. Enciclopédia Biosfera, v. 8, n. 15, p. 1913-1919, 2012. Disponível em:

<http://www.conhecer.org.br/enciclop/2012b/ciencias\%20biologicas/potencial\%20anti pantiprolifer.pdf>. Acesso em 02 de maio de 2017.

VICENTINI, V. E. P.; CAMPAROTO, M. L.; TEIXEIRA R. O.; MANTOVANI, M. S. Averrhoa carambola L., Syzygium cumini (L.) Skeels and Cissus sicyoides L.: medicinal herbal tea effects on vegetal and test systems. Acta Scientiarum, v. 23, p. 593-598, 2001.

Disponível em http://periodicos.uem.br/ojs/index.php/ActaSciBiolSci/article/view/2716> DOI: http://dx.doi.org/10.4025/actascibiolsci.v23i0.2716. 